\title{
The Comprehension of the Sexuality of the Brazilian and Portuguese Elderly, in the Nursing Consultation Context
}

\author{
Renata Jabour Saraiva ${ }^{1,}$, , Ann Mary Mary Machado Tinoco Feitosa Rosas², \\ Ermelinda Gonçalves Marques ${ }^{3}$, Geilsa Soraia Cavalcanti Valente ${ }^{4}$, Aline Furtado Da Rosa ${ }^{5}$ \\ ${ }^{1}$ Estácio de Sá University, Rio de Janeiro, Brazil \\ ${ }^{2}$ Federal University of Rio de Janeiro, Rio de Janeiro, Brazil \\ ${ }^{3}$ Polytechnic Institute of Guarda, Guarda, Portugal \\ ${ }^{4}$ Fluminense Federal University, Niterói, Brazil \\ ${ }^{5}$ Arthur Sá Earp Neto University, Petrópolis, Brazil \\ Email address: \\ renatajabour2014@gmail.com (R. J. Saraiva), annmaryrosas@gmail.com (A. M. M. M. T. F. Rosas), emarques@ipg.pt (E. G. Marques), \\ geilsavalente@yahoo.com.br (G. S. C. Valente), alinenfermagem@yahoo.com.br (A. F. Da Rosa) \\ ${ }^{*}$ Corresponding author
}

\section{To cite this article:}

Renata Jabour Saraiva, Ann Mary Mary Machado Tinoco Feitosa Rosas, Ermelinda Gonçalves Marques, Geilsa Soraia Cavalcanti Valente, Aline Furtado Da Rosa. The Comprehension of the Sexuality of the Brazilian and Portuguese Elderly, in the Nursing Consultation Context. American Journal of Nursing Science. Vol. 7, No. 2, 2018, pp. 49-53. doi: 10.11648/j.ajns.20180702.11

Received: November 8, 2017; Accepted: December 1, 2017; Published: March 5, 2018

\begin{abstract}
This present study aims to describe, understand and discuss subjectivity and intersubjectivity between nurses and clients in the educational action sexuality of the elderly in the context of the nursing consultation. The relevance was to listen to the elderly and nurses in the mentioned countries, with the intention of promoting reflections and probable changes of sharing, sharing experiences of the existing cultural plurality. It is a qualitative research, founded without theoreticalmethodological reference of the sociological phenomenology of Alfred Schutz. Participated 41 elderlies and 26 nurses. The scenarios were the HESFA- Brazil and the IPG -Portugal, in accordance with the ethical criteria, National Health Council, resolution 466/12. Resulted in concrete categories of lived that revealed the "reasons-why" of the elderly and nurses. Therefore, the absence of intention demonstrates the need to discuss the subject in theory since graduation and, in the practical field, in nursing consultations.
\end{abstract}

Keywords: Nursing, Consultation, Gerontology, Sexuality

\section{Introduction}

The article is current and relevant due to the absence of studies in the area of comprehensive analysis on the subject of the sexuality of the elderly in the Nursing Course, and can be evidenced through the state of the art. In this sense, we carried out a qualitative research, based on the theoreticalmethodological reference of the sociological phenomenology of Alfred Schutz

For these reasons, the study gave voice to the elderly, to understand the meaning of their sexuality, in the context of the nursing consultation, in their new moment of life. The objectives were to describe, understand and discuss subjectivity and intersubjectivity between nurses and clients in the educational action sexuality of the elderly in the context of nursing consultation.

\section{Understanding the Sexuality of Luso-Brazilian Elders}

\subsection{Population-Ageing}

The worldwide concern of United Nations (UN) experts in health, education, legal and social issues related to human aging has resulted in two assemblies: the first in 1982 and the 
second in 2002 in the cities of Vienna and Madrid respectively. Both are motivated by the need to find solutions and incentives to adapt to the changes arising from public policies, society and technological progress. In Brazil, the elderly is considered to be 60 years of age or older. The World Health Organization (WHO) has stated that by 2050 , there will be two billion people over 60 , long-lived, making it one of the greatest population successes in the 21 st century [1].

The Brazilian Institute of Geography and Statistics (IBGE) describes older people over 60 years of age, totaling 23.5 million, more than double that of 1991, when, in the same age group, there were 10.7 million. The participation of the population over 65 years old increased from $5.9 \%$ in 2000 to $7.4 \%$ in 2010 [2].

In this sense, it is believed that the motivations related to the elderly will guide the adoption of normative measures, facing the new global demographic reality of the 21 st century [3]. However, it is still necessary to take into account the specificities of the elderly in relation to their sexuality.

\subsection{A New Look for Luso-Brazilian Elders}

From this restlessness, the elderly was initially heard in Brazil and then in Portugal, with the intention of giving a new look to the study, taking into account being a country with a larger number of elderly, long-lived, and having a better quality of life. The data released by the last General Census of Population, promoted by the National Institute of Statistics (INGE), dated March 21, 2011 (considered in this elderly country the individual 65 years of age or older) indicate a decline in population of young people, standing at $15 \%$, while that of the elderly increased, occupying $19 \%$ of the total population [4].

These variations result in an imbalance, which leads to a decrease in the base of the demographic pyramid represented by the younger population and the enlargement of its top, which portrays the growth of the elderly population.

In listening to elderly people in Brazil and Portugal, was wanted, in addition to a new look, to promote reflective discussions that shared experiences and experiences in order to interact with the cultural plurality existing between the two countries, in order to help the understanding of the sexuality of this group and the possible changes of behaviors acquired after actions implemented in a learning situation. Considering the need for new models in the provision of health services that enable qualified care, which will require better training of professionals to take care of the health of the elderly in a way consistent with the current reality.

In analyzing the statistical data, we noticed that changes in the approach to sexuality of the elderly could be implemented both in Brazil and Portugal, contributing to the planning of services that meet the needs, rethinking the current system and adjusting it to the new realities, however, this reflection would need to be rapid, since this is also the way the aging of the population occurs.

\section{Method}

It is a qualitative research, based on the theoreticalmethodological reference of the sociological phenomenology of Alfred Schutz, whose importance is the use of methods that explore the maximum of the phenomena captured from the research. Their results are based on the real-life experiences of people with knowledge of the phenomenon first-hand [6].

The Phenomenology initiated by Edmund Husserl in the early twentieth century in Germany had the purpose of describing that all consciousness is intentional and that nothing is thinkable without reference to an act of consciousness and that the presence of the object in consciousness evidences knowledge. Thus, knowledge is explained as filling the intention. However, the final purpose of Husserl, according to Schutz, was to establish the creation of a philosophy without estimating, opting to study the experiences of the conscious human being who lives and acts in a "world", where he perceives and translates the phenomena for make it possible to make sense to him [10].

Considering the specificity of the thematic, it was chosen to make use of the Sociological Phenomenology of Alfred Schultz, for understanding adequately to articulate the article. For this, it was necessary to listen to nurses and the elderly, seeking their intentionality about sexuality, through the contextualization of the motive-because, with the intention of understanding the actions, planning and execution of singular activities in the nursing consultation [9].

The research was based on the dependencies of the Health Care Institution São Francisco de Assis (HESFA) - UFRJ Brazil, which works with the teaching of nursing consultation to the elderly, located in the city of Rio de Janeiro. And as a complement to the study scenario, there were data collection in Portugal, in three Day Centers; a Convivial Center; a Mixed Unit with Day and Home Center; a Family Health Unit; a Health Center; a Hospital and a Senior Academy in the City of Guarda in Portugal.

As inclusion criteria, 41 elders aged 60 and over, active, open to new technological trends facilitating their daily life, able to accept their new lifestyle through the programs of individual or group activities offered by the nurses in the scenarios indicated for research and who wish to talk about their sexuality, identified by I (elderly, plus the letter of the alphabet in the Portuguese language).

And the 24 nurses, identified by the letter E (nurses, plus the letter of the alphabet in the Portuguese language) selected for research, who are part of the Graduation and PostGraduation program, through nursing consultation to the elderly and who wish to talk about sexuality.

As a criterion for exclusion, elderly people who do not wish to participate as subjects of the research for claiming any reason that makes them unable to participate, and nurses who do not wish to participate as subjects because they are absent from the practice scenario for any reasons, such as: maternity leave, health care, among others, or even those who, although they are on the scene, do not develop teaching 
activity of the nursing consultation to the elderly for undergraduate and graduate nursing students. In this way, they were interviewed individually, through electronic recording (MP3). As a criterion of reliability, it was later allowed to listen to his interview.

For the data collection, the interview with a phenomenological approach, semi-structured, with an initial script was used, in which it was possible to understand the typical phenomenon of the participants of the research. It was understood in the light of Schutz that the intentionality of the participants and the understanding of the subjectivity and intersubjectivity provided by the empathy of the face-to-face relationship demonstrated at the time of the interviews made the genuine natural phenomena of human relations emerge without regard their values, providing an understanding of the contextualization of why-why and its categories [7].

For the organization of the data, aiming to arrive at the typical of the subjects' action, the phenomenological methodological trajectory of Alfred Schutz's theory was used, following the following steps: Apprehension of the speeches in the interviews, to describe the lived type of the subjects; Immediate transcription of the interviews, excluding Portuguese errors, aiming at preserving the subjectivity of the face-to-face research-participant relationship of the study; Careful and thorough reading, to transform what has proved subjective in purpose, with the purpose of grouping the meanings found in categories; Use cognomen, to express meanings, and to maintain anonymity; The intentionality of the lived type of the participants, through motives-for and motives-because.

This attitude represents the researcher's own activity in identifying, from the lines, the elaboration of concrete categories of the lived. Therefore, the typicity opens and closes according to the degree of anonymity and familiarity.

The development of the study met the standards according to Resolution 466/12, published on June 13, 2013, the participants of this research signed the Term of Free and Informed Consent. The interviews were carried out with the approval of the Committee of Ethics and Research (CEP) of the Anna Nery School of Nursing - Federal University of Rio de Janeiro, on 11/13/2014, under the number: 36876114.6.0000.5238.

The speeches of the participants of the research will be stored for a period of five years and discarded afterwards, respecting human opinion and dignity, involving the current and potential progress of science and technology, which should result in promotion of the well-being and the quality of life, as well as the defense and the preservation of the environment, for the present, as well as for the future generations.

\section{Results and Discussion}

Of the 26 nurses interviewed, 09 are teachers and accompany students in an internship field and 17 are nurse assistants, but all work with the elderly. Although 1 research participant is French, he graduated in Lisbon and did master's degree in Vizeu. Of the 26 interviewees, we found a greater number of nurses with a bracket between 57 and 60 years of age, and a total of 03 nurses close to the period of professional retirement, since in Portugal the minimum age to apply for retirement by age is 65 years. men and women.

In Brazil, retirement by age is a benefit due to the worker who proves the minimum of 180 months of work, besides the minimum age of 65 for men and 60 years for women. For the "special insured" (family farmer, artisanal fisherman, indigenous etc.), the minimum age is reduced by five years.

However, in the age group of 33 to 40 years, there are a total of 06 nurses, 02 are Brazilian and 07 are Portuguese, therefore, a greater number of new nurses contributing to the renewal of the profession.

The average age of nurses is similar between the two countries with the same teaching fundamentals regarding the sexuality of the elderly, as evidenced in the interviews and ratified by the data analysis, with the need for professional qualification to support both nurse practitioners the teaching nurse. Of the 26 nurses, 05 opted for Lato Sensu courses or to support the practice or to serve as a basis for the Stricto Sensu course.

Of the elderly interviewed, 17 were male and 24 were female, between the ages of 63 and 92. In relation to the marital status: 04 unmarried, 19 married, 03 separated and 15 widowed. Level of instruction: 02 uneducated elderlies, 14 elderlies with incomplete primary education, 19 with complete primary education, 03 with incomplete secondary education, 01 with complete secondary education, 01 with incomplete higher education and 01 with complete higher education. Just to draw a parallel between Brazil and Portugal, according to the elderly, the 1 st to 4 th class is equivalent to elementary school and the 5th to 9th grade is equivalent to secondary education.

Regarding the beginning of sexual life: two participants reported never having had sexual intercourse, while the other participants reported starting sexual life between 17 and 29 years.

As for naturalness: referring to Brazilians - 07 from Rio de Janeiro, 01 from Bahia and 01 from Minas Gerais - Brazil. Regarding the Portuguese: the 32 elders were born in villages that are part of the District of Guarda - Portugal. This statistical result plus the analysis of the speeches of the research participants showed that the Brazilian and Portuguese elderly people undergo the same physiological processes compatible with the course of aging in this phase of life.

Another relevant analysis occurs in relation to the majority of the elderly women being live, since in both Brazil and Portugal, these women lived a historical period of World War II, which justifies the high rate of widows. The counterpoint to this observation is that the change in women's lifestyle at the time was responsible for the liberal behavior of women throughout the ages, explaining the rates of single and separated elderly women in relation to the elderly.

It was proved from the results that the relationship of space and time established between the research participants and 
the interviewer revealed the contextualization of "reasonwhy" into categories.

However, in order to arrive at this methodological behavior, it is necessary to seek the basis of Schutz's concept of the "motive-for", in which the intention of the projected act must be realized by a future action.

After the analysis of the speeches, it was possible to understand and understand the meaning of the elderly in the educational action on the sexuality of the elderly in the context of the nursing consultation by making the study's "reason-why" emerge: a description of preconceived ideas and lack of understanding of the sexuality of the elderly and the influence of the cultural aspects involved in the context of the nursing consultation.

Thus, through the phenomenon itself, the following categories emerge after the comprehensive analysis: preconceived ideas between nurses and the elderly; interpretations on sexuality and sex between nurses and the elderly; aspects involved between nurses and the elderly.

\subsection{Category: Ideas Pre-Conceived Between Nurses and Seniors}

After the analysis, was observed that the meaning not understood by the nurses was neglected by the distorted ideas of sexuality and by assumptions, considering the elderly beings asexual and devoid of sexuality. This stereotype already established by society prevents the interpretation of the non-verbal signals transmitted at the moment of the faceto-face relationship, provided by the consultation context. This occurs when they relate preconceived ideas about the subject, justifying non-approach [8].

"I think it's an odd opportunity! Thus: taking into account the elderly clientele, so to speak. [...] a generation that really, sex was a taboo. Many preconceptions about talking about the subject, and in the nursing consultation I think the nurse has this opportunity [...]" [E-AA].

For Schutz [7], relationships interpreted by a "face-toface" relationship, such as the body of the other, events occurring in his body (blushing, smile), bodily movements, performed activities (walking, talking, manipulating things) can be seized as meanings.

In the context of the study, it would be the exchange of knowledge established in the teaching and learning process on sexuality, evidenced by the interrelation relationship established at the moment of the consultation.

\subsection{Category: Interpretations on Sexuality and Sex Between Nurses and the Elderly}

Sexuality encompasses more than the physical ability to have sexual intercourse. However, after the immersion of the interviews, we identified that the meaning of the words "sexuality" and "sex" still persists. However, those who know this complexity, because of the preconceived ideas, can not put it into practice.

In some cases, when the recorder was turned off, the study participants reported that they had not learned this complexity of the subject at undergraduate level and, in their professional experience, they felt the need, since there is a clinical tendency for disease prevention and health promotion to be replicated only in practice, but also in theory, of the vision of sexuality only as human behavior in the face of libido and sex as sexual relation, disassociated with human sexuality.

Often by the need expressed by the user himself. Other times the need we detected in the course of the consultation. "So today it is part of the nursing consultation script and we ask about the expression of sexuality, the difficulties that the person has, the question of pleasure $[\ldots]$ " [E-E].

\subsection{Category: Cultural Aspects Involved Between Nurses and the Elderly}

To understand the behavioral similarities of the study participants, we can not forget the cultural existence initiated by our own Portuguese language. In addition, due to our colonization, we inherited other traditions, such as the Catholic religion, the religious calendar, the cuisine, as well as important feasts such as the carnival and the June festivities. All these similarities can be understood as the world of the natural attitude. 6 A parallel is paralleled by colonization, the world of everyday life, considered as an intersubjective world, which already existed long before our birth and has already been tried and interpreted by our predecessors.

Thus, it is understood that from the analysis of the speeches, the stock of experiences the hand of the world in which we live, it is the life baggage of nurses.

"Of course if we think about sexuality only from the genital point of view we are reducing it completely to a dimension that is not the most acceptable, but if we also describe it from the point of view of affect or relational, we are also exploring other dimensions that are gifts. Eh! Also from a socio-cultural point of view, that's what we feel. Eh! In the strong, it marks because the sexual history and our sexual experience is determined and it is determinant in the approach that we do from the point of view of the sexuality of the old person" [E-AJ].

Despite public policies aimed at the elderly, nurses understand the need to work on the issue of sexuality, but they continue to re-signify it, as they did when they graduate. Therefore, it is the responsibility of preparing future qualified nurses to work at all levels of complexity of care for the human being in its entirety, in the context of the Unified Health System, in a critical-reflexive-creative perspective, committed to the promotion and prevention of pathologies inherent to the aging process, but adapting biopsychosocial issues related to sexuality.

Although the consultation was implemented by nursing nurses and teaching nurses, subjectivity and intersubjectivity, it was present by the contextualization of the "why-why" about the lack of compression of the meaning between sexuality and sex, relevant to establish health actions with preventive visions of pathologies specific to the aging process. 
Therefore, the intentionality about the educational action sexuality of the elderly, in the context of the nursing consultation, is typical for those people who understand and share looking for the coherent interpretation of the nurses on sexuality in relation to the elderly, with the acceptance of the approach as normal attitude of the aging process.

\section{Conclusions}

After studying the data of the nurses, it was verified that because they did not approach about sexuality in the context of the consultation of the elderly, there is a lack of a correct interpretation between the meaning of sexuality and sex, and the proof of the understanding, of preventive clinical care of nurses, only in relation to the pathologies related to sex.

However, when motivated by the questions of the script of semi-structured questions, they demonstrated an understanding of sexuality as affective relationships that provide quality of life. Thus, it appeared as a definition for nurses: the approach of the biomedical paradigm, based on humanization and biopsychosocial understanding about the sexuality of the elderly, with the intention of providing an active quality of life.

In addition, the results presented were in line with the professional and teaching practice in the line of research on the elderly, evidencing psychological, affective and cognitive manifestations, causing several physiological and mental consequences that can lead to psychic suffering, depression and even at death of the elderly. We realize that to feel alive again, the pulsar of energy, the pleasure of movement, and self-confidence, are elements that help the elderly to renew the meaning of life and the will to live. Key factors for psychosocial rehabilitation. Thus, throughout our research line, we verified the need for actions using technology, which could help nurses to provide quality of life for the elderly.

With the end of the thesis, and realizing the need of the elderly, continuing the research line, I started the postdoctoral stage with the development of an application, developed with a technological educational program, with the purpose of contributing to the process of promoting the health, disease prevention and identification of the elderly's priorities.

It has been proven that the elderly not only can, but also wish to receive new information related to their health care, with the help of technology. To meet this demand, we validated a mental health and quality of life questionnaire, available on Facebook, after the patent was filed, under the number: BR 1020170209385, targeting the elderly and their caregivers; researchers and health professionals. With this, we broaden our reflection on the quality of life of the elderly.

\section{References}

[1] United Nations Organization. Inclusion and public policies for the elderly. Brazil, 2012.

[2] National Institute of Geography and Statistics. Population Indicators. Portugal, 2014.

[3] Ministry of Health (Br). Department of Health Policies. Health Promotion Project. Health Promotion Letters. Brazil, 2012.

[4] National Institute of Geography and Statistics. Definitive Results. Brazil, 2012.

[5] Silva, GMD, Lima, SMRR \& Moraes JC. Evaluation of sexual function in postmenopausal women with metabolic syndrome. Revista Brasileira de Ginecologia e Obstetrícia. Vol. 35, No. 7, 2013, pp.301-8.

[6] Wagner, HTR. On phenomenology and social relations: The Alfred Schutz. Petrópolis: Vozes; 2012.

[7] Schutz, A. Bases of phenomenology. In: Wagner H, organizer. Phenomenology and social relations: texts chosen by Alfred Schutz. Rio de Janeiro: Zahar; 2012.

[8] Saraiva, R. J, Rosas, A. M. T. F, Marques, E. M. B. G, Valente, G. S. C. (2017). Outcome Thesis on sexuality of the elderly in the context of nursing consultation: a phenomenological analysis of Brazilians and Portuguese. Minutes of the 6th Ibero-American Congress on Qualitative Research (Volume 2 - Qualitative Research in Social Sciences). Oliveira de Azeméis - Aveiro - PORTUGAL: Ludomedia.

[9] Paula CC, Padoin SMM, Terra MG, Souza IEO, Cabral IV. Modes of conduction of the interview in phenomenological research: experience report. Rev Bras Enferm. 2014; 67(3):468-72.

[10] Jesus MCP, Capalbo C, Merighi MAB, Oliveira DM, Tocantins FR, Rodrigues BMRD et al. The social phenomenology of Alfred Schütz and its contribution for nursing. Rev Esc Enferm USP. 2013; 47(3):736-41. 